\title{
Engenharia urbana aplicada: um estudo sobre a qualidade do transporte público em cidades médias
}

\author{
Urban applied engineering: a study on quality of \\ public transport in mid-sized cities
}

Eloisa Maieski Antunes ${ }^{[0]}$, Fernanda Antonio Simões ${ }^{[b]}$

[a] Mestre em Engenharia Urbana, doutoranda em Geografia, pesquisadora convidada do laboratório Géographie Cités da Université Paris 1 Pantheón - Sorbonne, Paris - França, e-mail: eloisa@utfpr.edu.br

[b] Doutora em Engenharia de Transportes pela Universidade de São Paulo (USP), professora do Programa de Engenharia Urbana (PEU) da Universidade Estadual de Maringá (UEM), Maringá, PR - Brasil, e-mail: fasimoes@uem.br

\section{Resumo}

O presente trabalho mede o nível de satisfação dos usuários em relação ao sistema de transporte coletivo. Os atributos avaliados foram acessibilidade, tempo de viagem, lotação, pontualidade, sistema de informação, características dos veículos, comportamentos dos funcionários, segurança, confiabilidade, características das paradas de ônibus e satisfação geral e nos horários de pico. 0 questionário de opinião foi validado psicometricamente e, ao todo, foram 1.206 entrevistados nos municípios de Londrina (PR), Ponta Grossa (PR) e Cascavel (PR). Para calcular a fidedignidade desta pesquisa, utilizou-se o alfa de Cronbach e alfa da consistência interna (coeficiente de Pearson) e para a validação dos resultados utilizou-se a análise fatorial com o método de extração dos componentes principais com rotação varimax. Os resultados apontam que o maior índice de satisfação é em relação à distribuição geográfica dos abrigos de ônibus e o atributo de maior insatisfação é a lotação dos veículos. Conclui-se que, comparativamente, Londrina é o município que apresenta os melhores resultados.

Palavras-chave: Sistema de transporte. Qualidade. Cidades.

\section{Abstract}

The goal of the following work is to measure the satisfaction level concerning to the public transportation users. The issues evaluated were accessibility, travel time, capacity, timeliness, information system, vehicle characteristics, staff behaviors towards users, safety, maximum passengers capacity, buses stops' characteristics and overall satisfaction concerning to the peak times. The following work was applied in these sites location: Londrina (PR), Ponta Grossa (PR) and Cascavel (PR). The methodology used was a psychometric survey test and around of 1,206 people were interviewed. To calculate the accuracy of this research, we used the "Alpha Cronbach Test" and alpha internal consistency (Pearson correlation coefficient) and to validate the results, we used the extraction method of main components with the Varimax Rotation for factor analysis. The results show that the highest rate of satisfaction is in the geographical distribution of bus stops and the issue that 
we've notice greater dissatisfaction is the passenger capacity of the vehicles. So, we come to the conclusion that, relatively speaking, Londrina is the city that provides the best results.

Keywords: Transport system. Quality. Cites.

\section{Atributos da qualidade do sistema de transporte público urbano para ônibus}

A mobilidade urbana é fundamental para a qualidade de vida da população nas cidades brasileiras, porque os deslocamentos de pessoas são diários, frequentes e impactam diretamente na dinâmica urbana e no uso do solo urbano. A escolha do modal a ser utilizado depende das características próprias de cada um e da decisão final do usuário. Geralmente, o usuário deseja um transporte eficiente por meio do qual ele possa fazer seu deslocamento com qualidade e de forma eficiente.

Definir os atributos necessários para que o sistema de transporte público urbano por ônibus tenha indicadores de qualidade do serviço é uma tarefa complexa e multivariável. Cada parte envolvida, neste caso, os usuários e os gestores, tem visões distintas. No Brasil, os estudos que apontam os atributos necessários ao sistema de transporte público urbano por ônibus são: Candado (1995), Cardoso (2008), Faria (1985), Ferraz e Torres (2004), Lima Junior (1994), dentre outros. Cada autor utiliza ferramentas diferentes para avaliar o nível de qualidade dos serviços de transporte. 0 trabalho de Ferraz e Torres (2004) discorre sobre os principais atributos do sistema de transporte público, entre os quais pode-se citar: 1) acessibilidade, 2) tempo de viagem, 3) pontualidade, 4) lotação, 5) confiabilidade, 6) característica dos veículos, 7) características dos pontos de paradas, 8) segurança, 9) sistema de informação e 10) comportamento dos operadores.

A acessibilidade é a distância percorrida pelo usuário para iniciar e finalizar a viagem por transporte público e a comodidade experimentada nesse percurso (FERRAZ; TORRES, 2004). A acessibilidade está diretamente relacionada às características da rede, como sua configuração, localização e distância entre pontos de parada (SANTOS, 2008). A acessibilidade também pode ser avaliada considerando fatores como a existência de terminal central fechado ou aberto e o emprego de bilhetes-integração (FERRAZ, 1990).

A falta de acessibilidade pode gerar aflição e insegurança, Gonçalves (2000) menciona que, em muitas cidades, a ligação entre a origem e o destino das linhas do sistema de transporte nem sempre é clara; dessa forma, o usuário tem que descobrir sozinho o caminho desejado, o que gera desconforto.

0 segundo atributo é o tempo de viagem, definido como o tempo gasto no interior dos veículos. Depende da velocidade média, da distância percorrida (FERRAZ; TORRES, 2004) e da geometria das linhas. A velocidade depende da distância média entre pontos de parada, do grau de separação entre o transporte público e o tráfego em geral, das condições de trânsito e de rolamento proporcionada pela pavimentação das vias. A geometria das linhas depende das rotas: se são diretas, velocidade é maior; se sinuosas, a velocidade é menor (SAMPAIO; LIMA NETO, 2006).

0 terceiro atributo é a pontualidade, conceituada como a regularidade dos horários das linhas (FERRAZ; TORRES, 2004). Atrasos leves, de dois a três minutos, são geralmente perdoados pelos usuários, porém, atrasos maiores são vistos de forma muito negativa (FERRAZ, 1990).

O quarto atributo é a lotação, definida como a quantidade de passageiros no interior dos coletivos (FERRAZ; TORRES, 2004). A lotação excessiva traz alguns inconvenientes, porque viagens de grande duração realizadas de pé são cansativas, o contato corpóreo com outras pessoas causa desconforto e as operações de embarque/desembarque ficam mais difíceis de serem executadas.

0 quinto atributo é a confiabilidade no sistema de transporte público. É o grau de certeza dos usuários de que o veículo irá passar na origem e chegar ao destino (FERRAZ; TORRES, 2004). Ferraz (1990) afirma que diversos fatores podem ocasionar o não cumprimento dos horários de partida e chegada. 0 não cumprimento dos horários ou a não realização das viagens representam inconvenientes quanto 
menor for a frequência de atendimento. Em linhas de alta frequência, geralmente, o aspecto confiabilidade não é, em geral, afetado por pequenos atrasos ou adiantamentos.

O sexto atributo é a segurança, relacionado à frequência de acidentes e assaltos envolvendo veículos coletivos (FERRAZ; TORRES, 2004). Os roubos a ônibus, geralmente direcionados aos cobradores, constituem uma típica modalidade criminosa e costumam ser repetitivos em algumas localidades. Nessas áreas, o roubo a ônibus tem impacto na população, pois a experiência coletiva do medo, principalmente quando é muito frequente, tende a difundir uma sensação de impotência e de revolta na vida dos que utilizam esse meio de transporte (PESSOA; LIMA NETO, 2004).

O sétimo atributo é as características dos veículos que influenciam diretamente a percepção dos usuários sobre o conforto dos ônibus. A tecnologia e o estado de conservação dos veículos são fatores determinantes na comodidade dos usuários (FERRAZ; TORRES, 2004). 0 conforto é um conceito amplo e engloba tudo o que se refere ao bem-estar do usuário em relação ao transporte e à sua condição de operação. É determinado pela disponibilidade de assento, espaçamento entre assentos, solavancos, aceleração (KAWAMOTO, 1987), higiene, segurança, espaço para circulação interna, dimensões das portas, roleta, apoios, altura dos degraus e as condições ambientais, como conforto térmico, ruídos e iluminação (SANTOS, 2008).

A avaliação das condições ergonômicas, associada à pesquisa de opinião dos usuários é de fundamental importância para tradução das necessidades dos usuários em serviços. Santos (2009) realizou uma pesquisa para verificar quais são os aspectos negativos na opinião dos usuários. 0 resultado mostra que a altura das escadas para a pista no ônibus foi considerada elevada por mais de $50 \%$ dos usuários. Se o motorista para o ônibus próximo da calçada é mais fácil para os passageiros acessarem o veículo, porque diminui a distância entre o primeiro degrau e a guia, porém, nem sempre isso ocorre. A altura das escadas é um obstáculo principalmente para pessoas idosas, pois muitas têm mais dificuldade de locomoção.

Ferraz (1990) cita que o estado de conservação é avaliado principalmente pela limpeza, aspecto geral e existência de ruídos decorrentes do desgaste natural das peças ao longo da sua utilização. Em outro estudo, realizado por Ramos e Coelho (1998), no qual pesquisaram o que é essencial no sistema de transporte público sob o ponto de vista do usuário, concluíram que ter veículos em bom estado de conservação é fundamental.

O oitavo atributo é as características dos locais de paradas, relacionadas com a sinalização adequada e a existência de cobertura e bancos para sentar (FERRAZ; TORRES, 2004). 0 abrigo de ônibus é o primeiro elemento do sistema de transporte público que o usuário entra em contato é o elemento que vai encorajar as pessoas a usarem o transporte público. Pode ser transformado em algo engraçado e surpreso, além de oferecer conforto aos usuários e manter a visibilidade do usuário. As características esperadas pelos gestores nos abrigos de ônibus são: custo baixo, fácil manutenção, material resistente. Para o usuário, é relevante ter boa aparência, tamanho adequado, iluminação suficiente, distância adequada entre os pontos, localização adequada, informações sobre as linhas e horários. No planejamento desses abrigos devem-se observar as características citadas e as características ambientais como topografia, vegetação e clima (SUTHERLAND, 2008), por exemplo, em Dubai os pontos de ônibus tem ar-condicionado, sendo adaptados ao clima local.

Um detalhe técnico importante é em relação à radiação solar, cuja incidência não se dá apenas na vertical; em um abrigo de pequena proporção, deve-se levar em conta os raios solares na diagonal (PAZ, 2004). Em relação aos assentos, a extensão linear deles consiste em cerca de 1/3 do comprimento da cobertura, entre $1,60 \mathrm{~m}$ a 4,15 m, dependendo da quantidade de usuários que os utilizam. É importante salientar que os bancos não podem atrapalhar o trânsito de pedestres (SUTHERLAND, 2008).

A manutenção e limpeza são fatores precisam ser realizados periodicamente. Para que esses custos sejam cobertos, sugere-se fazer parcerias entre as empresas privadas e o responsável pela manutenção (geralmente são as prefeituras) para disponibilizar os abrigos como ferramentas de marketing. No Brasil essa política começou a ser utilizada em cidades como Ponta Grossa, São Paulo, Rio de Janeiro e Salvador.

A localização dos pontos de ônibus é muito importante, pois a distância de caminhada afeta a atração pelo serviço. Para que se tenha uma boa 
localização, recomenda-se que os abrigos sejam instalados em áreas de grande atração, em áreas comerciais e industriais. Deve-se tomar cuidado para não as instalar em lugares próximos a interseções, esquinas ou curvas, para evitar acidentes. A escolha da localização dos abrigos vai depender do tipo de zona e suas diferentes necessidades.

0 nono atributo é o sistema de informação do transporte. Envolve horários dos veículos, itinerários, informações sobre as linhas, informações no interior dos veículos (FERRAZ; TORRES, 2004). Marques (1995) cita que a identificação das características dos pontos de paradas, identificação da linha, número/código e croqui de itinerários são exigências mínimas nas instalações dos pontos de parada. Além disso, como equipamento urbano, um cesto para lixo é fundamental.

Por fim, o décimo atributo é a percepção dos usuários em relação ao comportamento dos operadores e outros funcionários. A pesquisa de Antunes, Graebin e Simões (2008) aponta que 89\% dos usuários do sistema de transporte público de Maringá consideram essencial que os funcionários da empresa prestadora de serviço sejam atenciosos e educados. Além disso, a pesquisa também aponta que $75 \%$ dos usuários acham essencial que a empresa ofereça atendimento diferenciado a idosos, gestantes e deficientes.

Sob o ponto de vista dos usuários, segundo a pesquisa de Aragão e Martinez (1995), o transporte público coletivo urbano deverá satisfazer os seguintes quesitos, por ordem de importância: confiabilidade, regularidade, pontualidade, disponibilidade, responsabilidade e informações. 0 pesquisador Santos (2008) considerou que o tempo de viagem, o intervalo entre atendimentos, a lotação, as características dos veículos, a facilidade de utilização e a mobilidade são os fatores mais importantes para a qualidade do sistema do transporte público urbano por ônibus. Rodrigues e Sorratini (2008) citam que os principais critérios de avaliação da qualidade para transporte público na visão do usuário são: confiabilidade (intervalo entre os veículos, tempo de viagem, cumprimento do itinerário), responsabilidade (substituição do veículo em caso de quebra, atendimento ao usuário), empatia (disposição do motorista e cobrador em dar informações, atenção com pessoas idosas e deficientes físicos), segurança (condução do motorista, assaltos), tangibilidade (lotação, limpeza, conservação), ambiente (trânsito, condições climáticas), conforto (bancos, iluminação, ventilação), acessibilidade (localização dos pontos de parada), preço (tarifa), comunicação (informação sobre o sistema, relação entre os usuários), imagem (identificação da linha/serviço), momentos de interação (contato com motorista/cobrador).

Definir os principais atributos de qualidade do sistema de transporte público urbano por ônibus, sob o ponto de vista do usuário, pode ser um instrumento complementar para o planejamento e a avaliação do sistema de transporte público coletivo. Para tanto, é preciso definir padrões de serviços aceitáveis para efeito de planejamento que agrade pelo menos a maioria dos clientes. Todos os atributos citados são percebidos pelos usuários de forma diferente; diante disso, podem ocorrer diversos problemas, como o risco dos clientes não perceberem corretamente o que foi realizado e, a partir daí, ficarem insatisfeitos ou supervalorizarem os resultados esperados.

A imagem de um dado serviço é formada por evidências, por experiências anteriores e pela troca de informações entre clientes, a chamada comunicação boca a boca. A escolha é influenciada pelas necessidades individuais, pela comunicação boca a boca e pela análise de evidências que possibilitam a inferência do provável desempenho do sistema (LIMA Jr., 1994). Nota-se, de modo geral, que as pesquisas têm atributos em comum que são usados para avaliar a qualidade do transporte público por ônibus de uma forma técnica. Utilizam-se índices e coeficientes para mensurar o atributo desejado, porém, poucas pesquisas incluem a opinião dos usuários como uma medida complementar e relevante para avaliar o sistema de transporte, pois o conhecimento das atitudes e dos valores dos usuários permite detectar possíveis falhas e desenhar políticas para melhorar o sistema de transporte coletivo.

Portanto, o objetivo desta pesquisa é conhecer o nível de satisfação dos usuários aplicando uma pesquisa de opinião nos municípios de Londrina (PR), Ponta Grossa (PR) e Cascavel (PR).

\section{Metodologia}

\section{Escolha dos atributos}

Para o desenvolvimento deste trabalho foram utilizados os atributos sugeridos por Ferraz 
e Torres (2004), já apresentados. Os atributos de satisfação geral e nos horários de pico foram incluídos conforme sugestão de Gonzalez, Pesqueira e Fernandez (2000).

\section{Instrumento de medida}

O instrumento de medida para realização desta pesquisa foi um questionário composto por 19 itens que avaliaram os atributos já citados, também foram coletados dados sobre faixa etária e renda dos usuários. Esse questionário foi validado psicometricamente, conforme a publicação de Antunes e Simões (2013) e sugestões de Gonzalez, Pesqueira e Fernandez (2000). A escala escolhida foi a de Likert, por ser a escala mais utilizada em pesquisa de opinião e a mais adequada para esse tipo de pesquisa. Foi dividida em foi de cinco ordens: discordo totalmente; discordo parcialmente; indiferente; concordo parcialmente e concordo totalmente.

0 instrumento avalia os atributos da seguinte forma:

1) acessibilidade (itens 1 e 2);

2) características dos veículos (itens 9,10 e 11);

3) comportamentos dos funcionários (itens 18 e 19);

4) segurança (itens 14 e 15);

5) confiabilidade (item 5);

6) características das paradas de ônibus (itens 12 e 13);

7) tempo de viagem (item 3);

8) lotação (item 7);

9) sistema de informação (itens 16 e 17);

10) pontualidade (item 4);

11) satisfação geral e nos horários de pico (itens 6 e 8).

Coleta de dados

Após o cálculo no número mínimo de amostra, foram selecionados os usuários de forma aleatória e em pontos distintos da cidade, para diminuir ao máximo as interferências. Os dias e horários selecionados foram de segunda a domingo, das $7 \mathrm{~h} 30$ às $19 \mathrm{~h}$, a fim de incorporar na amostragem diferentes tipos de usuários. Considerou-se como usuários pessoas acima de 14 anos e que utilizam o transporte pelo menos duas vezes na semana. A pesquisa foi realizada em março de 2009.

\section{Tratamento estatístico e psicométrico}

Foram desconsiderados os questionários com dados incompletos e/ou preenchidos de forma equivocada. Após análise de um gráfico Box-Plot desconsiderou os dados discrepantes para que a média não fosse distorcida de forma equivocada. Os dados foram analisados por meio do software Statistica 7, no qual foi criado um banco de dados com as respostas dos usuários do transporte público urbano. No primeiro momento, avaliaram-se as características socioeconômicas da população e, no segundo momento, procedeu-se a análise das atitudes dos usuários ante o sistema. Para o tratamento estatístico, calculou-se a média ponderada conforme os vários graus de concordância/discordância. Foram atribuídos números para indicar a direção da atitude do respondente. As respostas qualitativas com dados qualitativos foram numeradas de 1 a 5, deste modo: discordo totalmente (1), discordo parcialmente (2), indiferente (3), concordo parcialmente (4), concordo totalmente (5). Após foram atribuídos pesos de 1, 2, 0, 3 e 4 , respectivamente, para as assertivas favoráveis (positivas). Os valores foram invertidos quando a assertiva era desfavorável (negativa). Após o cálculo da média ponderada, classificou-se o nível de satisfação dos usuários de acordo com o intervalo matemático (Tabela 1).

Para calcular a fidedignidade dessa pesquisa, utilizou-se o alfa de Cronbach, que propõem um coeficiente geral que reflete o grau de covariância dos itens entre si, servindo, assim, de indicador da consistência interna do próprio teste Pasquali (2003).

Tabela 1 - Niveis de satisfação

\begin{tabular}{cc}
\hline Média ponderada & Nivel de satisfação \\
\hline 1 a 1,99 & Insatisfação \\
2 a 2,99 & Satisfação média \\
3 a 4 & Satisfação plena \\
\hline
\end{tabular}

Fonte: Dados da pesquisa. 
A fidedignidade ou a precisão de um teste diz respeito às características que ele deve possuir, a saber, a de medir sem erros. Medir sem erros significa que o mesmo teste, medindo os mesmos sujeitos em ocasiões diferentes, ou testes equivalentes, medindo os mesmos sujeitos na mesma ocasião, produzem resultados idênticos, isto é, a correlação entre estas duas medidas deve ser 1. Entretanto, como o erro está sempre presente em qualquer medida, esta correlação se afasta do 1 quando maior for o erro cometido na medida. A análise de precisão de um instrumento psicológico quer mostrar precisamente o quanto ele se afasta do ideal da correlação 1, de um determinado coeficiente que, quanto mais próximo de 1 , menos erro o teste comete ao ser utilizado (PASQUALI, 2003). Após, calculou-se o coeficiente de Pearson para conhecer a relação entre as variáveis.

Em seguida, foi realizada a validação dos resultados por meio da análise fatorial, com o método de extração dos componentes principais, com rotação varimax. Quanto à aplicação dessa técnica na amostra de tamanho $n,[x 1, x 2, \ldots, x n]$, é preferível se trabalhar com a matriz de correlação amostral $\mathrm{R}$, uma vez que, dessa forma, eliminam-se efeitos de escala das variáveis. Outro conceito muito importante é o do escore fatorial. Trata-se do valor supostamente assumido pelo fator $F j j=1,2, \ldots, n$, ou seja, $j$ variando de 1 até n-ésima para uma observação individual $x$. É importante mencionar também que, no caso de se desejar obter uma estrutura de fácil interpretação para os pesos, tal que cada variável tenha peso alto em um único fator e pesos baixos ou moderados nos demais fatores, é necessário fazer uma rotação rígida dos fatores (CARDOSO, 2004).

A rotação varimax foi escolhida, pois é importante obter fatores com a maior ortogonalidade possível, uma vez que o objetivo principal é medir componentes do construto satisfação com transporte público urbano com relativa independência entre si. Nesse método, os eixos dos fatores são rotados para uma posição na qual a soma da variação das cargas fatoriais é a máxima possível. Além disso, esse tipo de rotação minimiza o número de fatores em cada variável.

\section{Definição de amostra}

As fórmulas utilizadas para calcular o tamanho da amostra consideraram um erro amostral de 5\% e a margem de confiança de 95\% (Tabela 2). 0 cálculo da definição da amostragem está nas Equações 1 e 2.

$$
\begin{aligned}
& \mathrm{N}_{0}=\frac{1}{\varepsilon^{2}} \\
& n=\frac{\mathrm{N}_{0} \cdot \mathrm{N}}{\mathrm{N}_{0}+\mathrm{N}}
\end{aligned}
$$

Sendo: No = primeira aproximação da amostra; $\mathrm{N}$ = tamanho da população; = erro amostral; $\mathrm{n}$ = tamanho da amostra.

Tabela 2 - Número de usuários e da amostra

\begin{tabular}{lcccc}
\hline Cidade & $\begin{array}{c}\text { N. de usuários } \\
\text { por dia }\end{array}$ & Fonte & $\begin{array}{c}\text { N. mínimo } \\
\text { de usuários }\end{array}$ & $\begin{array}{c}\text { N. de usuários } \\
\text { entrevistados }\end{array}$ \\
\hline Londrina & 83.540 & CMTU & 398 & 399 \\
Ponta Grossa & 90.000 & VCG & 399 & 403 \\
Cascavel & 23.200 & CCT & 393 & 404 \\
\hline Total & & & & $\mathbf{1 . 2 0 6}$ pessoas \\
\hline
\end{tabular}

Fonte: Dados da pesquisa.

\section{Resultados}

Participaram da pesquisa 1.206 pessoas, com idades compreendidas entre 14 e 90 anos, procedentes de diferentes zonas da cidade. Em Ponta Grossa, participaram 403 pessoas com idades entre 14 e 87 anos, procedentes de diferentes zonas da cidade. Em relação à renda salarial, 25\% responderam que recebem até um salário mínimo por mês, $44,5 \%$ responderam ter uma renda entre um e dois salários mínimos, 18\% afirmaram que recebem entre dois e três salários apenas 12,5\% recebem acima de três salários.

Em Cascavel, participaram 405 usuários com idades compreendidas entre 14 e 76 anos, procedentes de diferentes zonas da cidade. Em relação à renda salarial, 29\% responderam que recebem até um salário, $39 \%$ responderam ter renda entre um e dois salários mínimos, $21 \%$ afirmaram receber entre dois e três salários e apenas 11\% recebem acima de três salários.

Em Londrina, a amostragem foi composta por 399 pessoas com idades compreendidas entre $14 \mathrm{e}$ 
90 anos, procedentes de diferentes zonas da cidade. Em relação à renda salarial, 25\% responderam receber até um salário mínimo, 44,5\% responderam ter renda entre um e dois salários, $18 \%$ afirmaram que recebem entre dois e três e apenas $12,5 \%$ recebem acima de três salários mínimos. Em relação à faixa etária da amostra total, 35\% eram usuários de 14 a 29 anos, $39 \%$ de 30 a 50 anos, $19 \%$ de 51 a 70 anos, e 7\% não responderam.

Fidedignidade do teste

A fidedignidade dos atributos utilizados nesta pesquisa foi testada por meio do cálculo do coeficiente Alfa de Cronbach que mede a consistência interna do teste. Segundo Litwin (1995) o teste de confiabilidade é imperativo e mede o desempenho de um instrumento em uma população evitando o agrupamento de questões aparentemente relevantes. 0 alfa de Cronbach em cada município pode ser visualizado na Tabela 3.

Tabela 3 - Alfa de Cronbach em cada município

\begin{tabular}{lc}
\hline Cidade & Alfa de Cronbach \\
\hline Londrina & 0,86 \\
Ponta Grossa & 0,83 \\
Cascavel & 0,80 \\
\hline
\end{tabular}

Fonte: Dados da pesquisa.

Conforme Évrard (1993), são aceitáveis valores de alfa entre 0,60 e 0,80 para estudos exploratórios. No caso de estudos confirmatórios, são recomendados alfas superiores a 0,80. Nesse sentido, considera-se o instrumento utilizado como sendo confiável, uma vez que, em todas as cidades, apresentou alfa superior a 0,80 . A cidade que obteve o maior alfa de Cronbach foi Londrina, e o menor, em Cascavel. Esse número revela que o instrumento apresenta índices aceitáveis de consistência interna, ou seja, os itens mensuram os mesmos aspectos do objeto na investigação.

Em continuidade da análise, calculou-se o valor da consistência interna (coeficiente de Pearson) caso o item fosse eliminado. Na Tabela 4, tem-se o alfa se o item for suprimido de cada município, em cada item do questionário. Quanto mais próximo de 1, indica grau maior de relação das variáveis em estudo. 0 maior valor de alfa refere-se à lotação dos ônibus, e o menor, à satisfação geral dos usuários.

$\mathrm{Na}$ análise fatorial, escolheu-se o item que apresentava uma carga fatorial maior de 0,50 o qual representa bem um fator comportamental e indica grau de correlação significante entre a variável e o fator considerável. 0 resultado indica o agrupamento em oito fatores, os quais explicam $68,77 \%$ do total da variância para a cidade de Londrina, 66,02\% para Ponta Grossa e 64,98\% para Cascavel.

Os resultados do nível de satisfação de cada item avaliado podem ser visualizados na Tabela 5. Eles indicam o nível de satisfação em cada município.

\section{Discussão dos resultados}

O nível de satisfação do atributo acessibilidade foi medido pelos itens 1 e 2 . 0 resultado do item 1 indica que 41\% dos usuários de Ponta Grossa, $54 \%$ dos usuários de Londrina e 44\% dos usuários entrevistados de Cascavel estão plenamente satisfeitos com a proximidade dos pontos de ônibus.

Tabela 4 - Variável Observável e alfa se suprimido por cidade

\begin{tabular}{llccc}
\hline & Item & Ponta Grossa & Londrina & Cascavel \\
\hline 01 & Os pontos de ônibus ficam próximos a sua casa/trabalho & 0,81 & 0,85 & 0,78 \\
02 & É fácil o acesso a diversos bairros & 0,81 & 0,84 & 0,77 \\
03 & É rápido o deslocamento do bairro até o centro & 0,81 & 0,84 & 0,77 \\
04 & Os ônibus são pontuais & 0,80 & 0,84 & 0,77 \\
05 & Quando tenho pressa utilizo o ônibus & 0,81 & 0,85 & 0,78
\end{tabular}


Tabela 4 - Variável Observável e alfa se suprimido por cidade

(Conclusão)

\begin{tabular}{|c|c|c|c|c|}
\hline & Item & Ponta Grossa & Londrina & Cascavel \\
\hline 06 & Estou satisfeito com o serviço de ônibus do horário de pico & 0,80 & 0,84 & 0,76 \\
\hline 07 & Os ônibus são lotados & 0,83 & 0,87 & 0,80 \\
\hline 08 & Estou satisfeito com o serviço de ônibus na cidade & 0,80 & 0,84 & 0,76 \\
\hline 09 & Andar de ônibus é confortável & 0,80 & 0,84 & 0,77 \\
\hline 10 & Os ônibus estão limpos & 0,80 & 0,84 & 0,77 \\
\hline 11 & Os ônibus estão em bom estado de conservação & 0,80 & 0,84 & 0,76 \\
\hline 12 & Os pontos de ônibus são agradáveis de ficar & 0,80 & 0,85 & 0,77 \\
\hline 13 & 0 número de paradas de ônibus é suficiente & 0.81 & 0,85 & 0,77 \\
\hline 14 & Acho seguro andar de ônibus em relação a acidentes & 0,81 & 0,85 & 0,77 \\
\hline 15 & Sinto-me seguro em relação a roubos & 0,81 & 0,85 & 0,77 \\
\hline 16 & Estou satisfeito com as informaçōes nos pontos de ônibus & 0,80 & 0,85 & 0,76 \\
\hline 17 & As informaç̃ōes no terminal são suficientes & 0,80 & 0,85 & 0,77 \\
\hline 18 & Os motoristas e cobradores são educados & 0,80 & 0,84 & 0,77 \\
\hline 19 & 0 motorista costuma frear e acelerar suavemente & 0,81 & 0,85 & 0,77 \\
\hline
\end{tabular}

Fonte: Dados da pesquisa.

Tabela 5 - Nível de satisfação

\begin{tabular}{|c|c|c|c|c|}
\hline & Item & Ponta Grossa & Londrina & Cascavel \\
\hline 1 & Os pontos de ônibus ficam próximos a sua casa/trabalho & 2,96 & 3,10 & 2,94 \\
\hline 2 & É fácil 0 acesso a diversos bairros & 2,11 & 2,52 & 2,15 \\
\hline 3 & É rápido o deslocamento do bairro até o centro & 2,34 & 2,54 & 2,22 \\
\hline 4 & Os ônibus são pontuais & 2,28 & 2,27 & 2,16 \\
\hline 5 & Quando tenho pressa, utilizo o ônibus & 2,05 & 1,96 & 1,90 \\
\hline 6 & Estou satisfeito com o serviço de ônibus do horário de pico & 1,75 & 1,99 & 1,87 \\
\hline 7 & Os ônibus são lotados & 1,85 & 1,87 & 1,62 \\
\hline 8 & Estou satisfeito com o serviço de ônibus na cidade & 2,00 & 2,31 & 1,83 \\
\hline 9 & Andar de ônibus é confortável & 1,71 & 1,89 & 1,65 \\
\hline 10 & Os ônibus estão limpos & 2,09 & 2,59 & 2,17 \\
\hline 11 & Os ônibus estão em bom estado de conservaç̦̃ó & 2,42 & 2,64 & 2,48 \\
\hline 12 & Os pontos de ônibus são agradáveis de ficar & 1,99 & 1,84 & 1,65 \\
\hline 13 & 0 número de paradas de ônibus é suficiente & 2,50 & 2,59 & 2,23 \\
\hline 14 & Acho seguro andar de ônibus em relação a acidentes & 2,28 & 2,80 & 2,30 \\
\hline 15 & Sinto-me seguro em relação a roubos & 1,94 & 1,71 & 1,85 \\
\hline 16 & Estou satisfeito com as informaçōes nos pontos de ônibus & 1,94 & 1,91 & 1,62 \\
\hline 17 & As informaç̃ōes no terminal são suficientes & 2,42 & 2,42 & 2,38 \\
\hline 18 & Os motoristas e cobradores são educados & 2,59 & 2,66 & 2,49 \\
\hline 19 & 0 motorista costuma frear e acelerar suavemente & 2,21 & 2,17 & 2,18 \\
\hline
\end{tabular}

Fonte: Dados da pesquisa. 
A boa distribuição geográfica dos abrigos de ônibus é importante porque o ponto de embarque/ desembarque é a porta de entrada do usuário para o sistema de transporte público coletivo. Essa proximidade pode ser usada como algo motivador, aproximando o usuário com o meio de transporte.

Em Londrina, quando o resultado é estratificados por renda, observa-se que a população com renda entre três e quatro salários estão insatisfeitas. Em Cascavel, observa-se que a população com renda entre dois e três salários também apresentam insatisfação, com um índice de 1,86.

0 item 2 do questionário também está relacionado à acessibilidade do sistema de transporte público. 0 resultado indica satisfação média nas três cidades. Em Ponta Grossa, 23\% dos usuários discordam totalmente, $20 \%$ discordam parcialmente, $13 \%$ são indiferentes, $29 \%$ concordam parcialmente e $16 \%$ concordam totalmente. Em Londrina, 20\% dos usuários discordam totalmente, 19\% discordam parcialmente, $6 \%$ são indiferentes, $25 \%$ concordam parcialmente e 30\% concordam totalmente. Em Cascavel, 23\% dos usuários discordam totalmente, $20 \%$ discordam parcialmente, $11 \%$ são indiferentes, $28 \%$ concordam parcialmente e $17 \%$ concordam totalmente.

Quando os dados são estratificados por idade, o público da cidade de Cascavel que tem idade entre 14 a 29 anos, apresentam nível de satisfação plena. Entretanto, em Londrina, o público que tem idade entre 30 e 50 anos estão insatisfeito com este quesito, sentem maiores dificuldades de deslocamente entre os bairros da cidade.

Durante a pesquisa, observou-se o deslocamento dos deficientes físicos e sensoriais, de uma forma geral. Quando foram entrevistados, concordavam que o sistema de transporte público é acessível para eles, apesar de suas limitações óbvias. Em todas as cidades estudadas existem alguns ônibus que disponibilizam espaço para cadeirantes.

O nível de satisfação do atributo tempo de viagem foi medido pelo item 3, o objetivo era saber se os usuários consideram rápido o deslocamento do bairro até o centro. 0 resultado indica que os usuários de todas as cidades estão satisfeitos de forma média. Com exceção do público de Cascavel com idade acima de 51 anos apresenta nível de insatisfação $(1,71)$ diferenciando-se em outras faixas etárias.
0 nível de satisfação do atributo pontualidade medido pelo item 4 que aponta satisfação média em todas as cidades e não teve variações significativas dentre elas. Em relação à estratificação por idade e renda, também não houve alterações.

0 item 5 mediu o nível de satisfação do atributo confiabilidade dos usuários. A questão perguntava se os usuários utilizam o sistema de transporte quando têm pressa, 34\% dos usuários de Ponta Grossa, 45\% dos usuários de Londrina e 41\% dos usuários de Cascavel responderam que não usam o transporte quando a situação requer agilidade. Ponta Grossa é a cidade que apresenta o melhor resultado em relação às outras cidades. Isso pode ser um indicador de que há poucos atrasos nas linhas e que o sistema tem uma frequência de atendimento adequado à necessidade dos usuários.

0 atributo lotação, determinado pelo item 7 , apresenta nível de insatisfação alto dos usuários em todas as cidades, em todas as faixas etárias e de renda. Os usuários insatisfeitos correspondem a 53\% em Ponta Grossa, 58\% em Londrina e 63\% em Cascavel. A pesquisa de Antunes, Graebin e Simões (2008) apontam que 96\% dos usuários acreditam que é essencial que a empresa operadora respeite a lotação máxima dos veículos.

0 nível de satisfação do atributo características dos veículos foi medido pelos item 9, 10 e 11.0 item 9 , vinculado ao estado de conforto dos veículos indica que nenhuma cidade atingiu a pontuação mínima para ser classificada como satisfatório $45 \%$ dos usuários em Ponta Grossa, 41\% em Londrina e 47\% em Cascavel estão insatisfeitos plenamente. Apenas 11\% dos usuários de Cascavel e Ponta Grossa e 10\% dos usuários de Londrina responderam que estão satisfeitos. 0 item 10 questionava sobre a limpeza dos ônibus. De uma forma geral, os usuários estão satisfeitos em todos os municípios. 0 item 11 perguntou aos usuários se os ônibus estão em bom estado de conservação. Em Londrina, os usuários acima de 50 anos apresentam nível de satisfação 3,41 considerada como satisfação plena. Os demais públicos das cidades estudadas apresentam satisfação média. Em Ponta Grossa, 33\% concordam parcialmente e $23 \%$ concordam totalmente; em Londrina, $29 \%$ concordam parcialmente e $29 \%$ concordam totalmente; e em Cascavel, $34 \%$ concordam parcialmente e $25 \%$ concordam totalmente. 
O nível de satisfação do atributo características dos veículos foi medido pelos itens 12 e 13 . No item 12 , observa-se que em todas as cidades é alto o nível de insatisfação, 35\% em Ponta Grossa, 45\% em Londrina e 51\% em Cascavel estão insatisfeitos totalmente. Ponta Grossa é o município onde os usuários estão menos insatisfeitos em relação às paradas de ônibus. As características dos pontos de ônibus são importantes e interferem na percepção de conforto dos usuários. A questão 13, que pergunta aos usuários se o número de paradas é suficiente, aponta que os usuários de todas as cidades estão satisfeitos. A proximidade e a distribuição dos pontos de ônibus são satisfatórias em todas as cidades estudadas, o que falta é a melhoria das condições dos pontos de ônibus.

O nível de satisfação do atributo segurança foi medido pela variável 14 e 15 . 0 resultado do item 14 indica que de uma forma geral os usuários estão satisfeitos, em Londrina $41 \%$ dos usuários se sentem seguros em relação a acidentes. Entretanto, no quesito segurança em relação a roubos (item 15), percebe-se que a população sofre certa insegurança, graças ao aumento da criminalidade. Apesar de a violência urbana ser um problema fora do escopo do sistema de transporte, isso acaba refletindo na relação dos usuários com o transporte público. A pesquisa aponta que, de forma geral, os usuários estão insatisfeitos com esse quesito. Porém, quando os dados são estratificados por idade, observa-se que a população entre 30 e 50 anos de Ponta Grossa está satisfeita e a população acima de 51 anos do município de Cascavel também.

O nível de satisfação do atributo sistema de informação foi medido pelos itens 16 e 17. 0 item 16 questionou se os usuários estão satisfeitos com as informações nos pontos de ônibus. 0 resultado mostra que 32\% dos usuários de Ponta Grossa, 37\% de Londrina e 34\% de Cascavel estão plenamente insatisfeitos. Em relação ao sistema de informação nos pontos de ônibus (item 17), as cidades apresentam grau de satisfação mediana.

O nível de satisfação do atributo comportamento dos operadores foi medido pelos itens 18 e 19.0 item 18 perguntou aos usuários se os motoristas e cobradores são educados. Observa-se que, de modo geral, os usuários estão satisfeitos com a prestação de serviço dos motoristas e cobradores nas cidades estudadas. 0 maior nível de satisfação é na cidade de Londrina (33\%), seguido por Ponta Grossa (32\%) e
Cascavel (32\%). Em relação ao item 19, que perguntou aos usuários se os motoristas costumam frear e acelerar suavemente, indica resultado satisfatório em todas as cidades.

O item 8 perguntou aos usuários se estão satisfeitos com o serviço de ônibus na cidade. 0 objetivo era medir, de forma geral, a satisfação do usuário com o sistema de transporte público. 0 maior nível de satisfação é em Londrina, seguido por Ponta Grossa e Cascavel. Em Cascavel, os usuários estão mais insatisfeitos com o sistema de transporte público. Esse fato está ligado às deficiências do sistema que não atingiram índices de satisfação como: lotação, conforto nos ônibus e pontos de ônibus, sistema de informação nos terminais, dentre outros. Em relação à variável 6, a qual perguntou aos usuários se estão satisfeitos com o serviço de ônibus nos horários de pico, indica insatisfação em todas as cidades e em todas as faixas etárias. A insatisfação pode ser gerada por vários motivos, porém, a lotação dos ônibus que é a principal reclamação dos usuários.

\section{Considerações finais}

O objetivo central deste estudo foi avaliar o nível de satisfação dos usuários em relação ao sistema de transporte urbano por ônibus em três cidades médias. Conhecer as atitudes e a avaliação da população frente ao sistema de transporte contribui para disseminação de uma gestão mais eficiente e satisfatória. Diante do estudo realizado conclui-se que o município que apresenta maiores índices de satisfação em ordem decrescente é Ponta Grossa, Londrina e Cascavel. De uma forma geral, os atributos que apresentam níveis de satisfação em todas as cidades são: acessibilidade, comportamento dos operadores, tempo de viagem e pontualidade. 0 atributo satisfação geral apresenta níveis de satisfação mediano em Londrina e Ponta Grossa, porém a insatisfação em horários de pico é alta em todas as cidades.

O sistema de transporte público em Cascavel apresenta várias deficiências em relação à lotação, frequência no horário de pico, conforto nos ônibus e pontos de paradas e ao sistema de informação. É importante ressaltar que todas as cidades apresentam deficiências no sistema de transporte público, porém as comparando Cascavel obtêm os piores resultados. 
Em relação ao atributo características dos veículos o item que apresenta insatisfação é em relação ao conforto nos veículos. Os aspectos de limpeza e estado de conservação são vistos de forma positiva pelos usuários. 0 sistema de informação nos pontos de ônibus é visto como precário nas três cidades. Por outro lado, a distribuição dos pontos de ônibus é satisfatória. Portanto, conclui-se que há uma ótima distribuição geográfica dos pontos o que realmente falta é a melhoria das condições dos abrigos.

0 atributo confiabilidade não atingiu nível de satisfação médio em Cascavel, mas em Ponta Grossa e Londrina os usuários estão satisfeitos. Sugere-se, para uma pesquisa futura, analisar quais os fatores que interferem na percepção do público de Cascavel.

De forma geral, o atributo que gera maior insatisfação está relacionado com a lotação. Essa evidência também pode ser confirmada pelo resultado de insatisfação nos horários de pico onde o número de usuários é maior.

Esta pesquisa apresenta os níveis de satisfação em três municípios de cada atributo escolhido do sistema de transporte público por ônibus. É interessante salientar que os resultados podem desenhar algumas deficiências do sistema sob o ponto de vista dos usuários.

\section{Referências}

ANTUNES, E. M; GRAEBIN, T.; SIMOES, F. A. Levantamento da expectativa do usuário de transporte público coletivo por ônibus em relação ao atendimento, ambiente e operação. In: ENDITEC - ENCONTRO NACIONAL DE DIFUSÃO TECNOLÓGICA, 5., 2008, Medianeira. Anais... Medianeira: Enditec, 2008.

ANTUNES, E. M; SIMOES, F. A. Utilização da psicometria para avalia a qualidade do serviço de transporte: um estudo de caso. Revista Gestão Industrial, v. 9, n. 2, 420445, 2013.

ARAGÃO, J. J. G.; MARTINEZ, C. A. A Interação entre prepostos e passageiros como momento de qualidade dos serviços de transportes público coletivo urbano: um estudo de caso no Distrito Federal. In: CONGRESSO DE PESQUISA E ENSINO EM TRANSPORTES, 9., 1995, São Carlos. Anais... São Carlos: Anpet, 1995. p. 652-659. v. 2.
CANDADO, V. L. Levantamento de opinião dos usuários em relação aos atributos dos transporte por ônibus. In: CONGRESSO DE PESQUISA E ENSINO EM TRANSPORTES, 9., 1995, São Carlos. Anais... São Carlos: Anpet, 1995. p. 1004-1014.

CARDOSO, C. E. P. Análise do transporte coletivo urbano sob a ótica dos riscos e carências sociais. 2008. 123f. Tese (Doutorado em Serviço Social) — Pontifícia Universidade Católica de São Paulo, São Paulo, 2008.

CARDOSO, F. A. R. Análise da qualidade no setor de serviço segundo o método de avaliação SERVQUAL. 2004. 186 f. Dissertação (Mestrado em Métodos Numéricos em Engenharia) - Universidade Federal do Paraná, Curitiba, 2004.

ÉVRARD, Y. La satisfaction du consommateur: état des recherches. Revue Française du Marketing, v. 4-5, n. 144 145, p. 53-65, 1993.

FARIA, C. A. Percepção do usuário com relação às características do nível de serviço do transporte coletivo urbano por ônibus. 1985. 160 f. Dissertação (Mestrado em Engenharia) - Universidade de São Paulo, São Carlos, 1985.

FERRAZ, A. C. P. Sobre a eficiência e a eficácia do transporte público nas cidades médias. Tese (Livre docência em Engenharia) - Universidade de São Paulo, São Carlos, 1990.

FERRAZ, A. C. P.; TORRES, I. G. E. Transporte público urbano. São Carlos: Rima, 2004.

GONÇALVES, A. R. Avaliação de sistemas integrados de transporte público coletivo: estudo de caso de quatro cidades brasileiras. 2000. Dissertação (Mestrado em Transporte) - Universidade de Brasília, Brasília, 2000.

GONZALEZ, M. S. R.; PESQUEIRA, G. S.; FERNANDEZ, C. A. Construcción y análisis de um cestionario de evaluación de los medios de transporte público. Psicothema, v. 12, n. 3, p. 399-405, 2000.

KAWAMOTO, E. Um novo enfoque do processo de escolha em transporte com tratamento baseado na psicofísica multidimensional. 1987. 126 f. Tese (Doutorado em Engenharia) - Universidade de São Paulo, São Carlos, 1987.

LIMA JUNIOR, O. F. Qualidade em serviços de transportes: manual técnico da qualidade da Universidade de São Paulo. Brasília: Ministério dos Transportes, 1994. 
LITWIN, M. S. How to measure survey reability and validity. London: Sage Publications, 1995.

MARQUES, H. N. Um sistema de informações para usuários de transporte coletivo em cidades de médio porte. 1995. 96 f. Dissertação (Mestrado em Engenharia) — Universidade de São Paulo, São Carlos, 1995.

PASQUALI, L. Psicometria: teoria dos testes na psicologia e na educação. Petrópolis: Vozes, 2003.

PAZ, D. J. M. O. 0 cidadão ausente. A cidade de Salvador e os seus abrigos de ônibus. Arquitextos, v. 5, nov. 2004. Disponível em: <http://www.vitruvius.com.br/revistas/ read/arquitextos/05.054/528>. Acesso em: 16 out. 2013.

PESSOA, R. C.; LIMA NETO, O. C. C. Análise da violência no transporte coletivo por ônibus na região metropolitana do Recife. In: CONGRESSO DA ASSOCIAÇÃO NACIONAL DE PESQUISA E ENSINO EM TRANSPORTES, 18., 2004, Florianópolis. Anais... Florianópolis: Anpet, 1996. Disponível em: <http://www.cbtu.gov.br/estudos/ pesquisa/anpet_xviiiCongrpesqens/rt/RD_arq45.pdf>. Acesso em: 16 out. 2013.

RAMOS, R. E. B.; COELHO, V. L. Características de qualidade do serviço de transporte intermunicipal de passageiros. In: ENCONTRO DA ASSOCIAÇÃO NACIONAL DE PÓS-GRADUAÇÃO E PESQUISA EM ADMINISTRAÇÃO ENANPAD, 22., 1998, Foz do Iguaçu. Anais... Foz do Iguaçu: Anpad, 1998.
RODRIGUES, M. A; SORRATINI, J. A. A qualidade no transporte coletivo urbano. In: CONGRESSO DE PESQUISA E ENSINO EM TRANSPORTES, 22., 2008, Fortaleza. Anais... Fortaleza: Anpet, 2008. p. 1081-1092.

SAMPAIO, B. R; LIMA NETO, O. Eficiência na gestão do transporte público: lições para o planejamento institucional. Revista Planejamento e Políticas Públicas, n. 29, p. 101-122, jun./dez. 2006.

SANTOS, A. D. Ergonomia dos ônibus urbanos: estudo de caso na cidade de Santos. 2009. Disponível em: <www.ergopro.com.br/artigos/(1).pdf>. Acesso em: 1 maio 2009.

SANTOS, B. J. R. A qualidade no serviço de transporte público urbano. 2008. Disponível em: <www2.ucg.br/ nupenge/pdf/Benjamim_Jorge_r.pdf>. Acesso em: 12 jun. 2008.

SUTHERLAND, S. C. Development Control Plant - Bus Shelters and Saets. 2008. Disponível em: <www.sutherlandshireconcuncil.com>. Acesso em: 30 maio 2008.

Recebido: 31/07/2013

Received: 07/31/2013

Aprovado: 20/09/2013

Approved: 09/20/2013 